\title{
Xanthogranulomatous prostatitis: a mimic of carcinoma of prostate
}

\author{
Muhammad Rafique*1,3 and Nausheen Yaqoob ${ }^{2}$
}

Address: ${ }^{1}$ Department of Urology, Nishtar Medical College, Multan, Pakistan, ${ }^{2}$ Department of pathology, Agha Khan University Hospital, Karachi, Pakistan and 35, Altaf Town, Tariq Road. Multan, Pakistan

Email: Muhammad Rafique* - rafiqanju@hotmail.com; Nausheen Yaqoob - Nausheen.yaqub@aku.edu

* Corresponding author

Published: 05 June 2006

World Journal of Surgical Oncology 2006, 4:30 doi:10.1 186/1477-7819-4-30

This article is available from: http://www.wjso.com/content/4/I/30

(c) 2006 Rafique and Yaqub; licensee BioMed Central Ltd.

This is an Open Access article distributed under the terms of the Creative Commons Attribution License (http://creativecommons.org/licenses/by/2.0), which permits unrestricted use, distribution, and reproduction in any medium, provided the original work is properly cited.

\begin{abstract}
Background: Xanthogranulomatous prostatitis is an unusual benign inflammatory process of prostate. Clinically it mimics prostatic carcinoma, requiring pathological examination for diagnosis.

Case presentation: A 60 -year-old patient presented with 6 months history of increasing difficulty in micturition. On digital rectal examination prostate was hard and nodular and estimated weight was 50 -gram. His serum prostate specific antigen (PSA) was $150 \mathrm{ng} / \mathrm{ml}$. Clinically a locally advanced carcinoma of prostate was suspected. In view of severe obstructive urinary symptoms and significant post-micturition residual urine, transurethral resection of prostate was carried out. Histopathological examination of resected prostatic tissue revealed xanthogranulomatous prostatitis with no evidence of malignancy. Patient remains symptom free at 16 months follow-up and serum PSA has decreased to $6 \mathrm{ng} / \mathrm{ml}$.
\end{abstract}

Conclusion: Xanthogranulomatous prostatitis is a benign inflammatory disorder of prostate that can clinically and even biochemically mimic prostatic carcinoma. A high degree of suspecion and close co-operation with pathologist is necessary for the diagnosis of xanthogranulomatous prostatitis.

\section{Background}

A variety of the granulomatous lesions of the prostate have been described with varied etiology and pathogenesis [1]. Xanthogranulomatous prostatitis is one such rare benign inflammatory lesion of prostate that can clinically mimic prostatic carcinoma. Sometimes condition may be mistaken for high-grade prostatic carcinoma [2].

Herein we report a patient who had xanthogranulomatous prostatitis but initially on clinical and biochemical grounds, he was mistakenly diagnosed to be case of locally advanced prostatic carcinoma.

\section{Case presentation}

A 60-years-old man presented with 6 months history of increasing difficulty in micturition, He had hesitancy, weak flow, intermittency and increased urinary frequency. His American Urinary Association (AUA) symptom score was 24 , consistent with severe prostatic symptoms. He had no significant past medical history and was non-diabetic. His general physical examination was normal. On digital rectal examination prostate was enlarged with approximate weight of 50 grams. It was non tender and felt hard and nodular. A provisional diagnosis of locally advanced prostatic carcinoma was made. His renal function tests and complete blood counts were normal. Eryth- 
rocyte sedimentation rate (ESR) was elevated at $55 \mathrm{~mm}$ at 1 hour. Routine urinalysis revealed 8-10 WBC's/hpf but urine culture was negative. PSA was significantly elevated at $150 \mathrm{ng} / \mathrm{ml}$ (normal 0-4 ng/ml). At transabdominal ultrasonography he had normal upper renal tract. Bladder was thick walled and prostate was $5 \times 5 \times 4 \mathrm{Cm}$ in size and was rather uniformly hypoechoic. Post-micturition residual urine was $160 \mathrm{ml}$. His chest, plain X-ray KUB and radioisotope bone scan was normal. Urine flow rate at flowmetry was $12 \mathrm{ml} / \mathrm{sec}$.

In view of the troublesome obstructive urinary symptoms, significant residual urine, needle biopsies were not performed and he underwent cystoscopy and transurethral resection of prostate (TURP). At cystoscopy, prostatic urethra was inflamed. Prostate was quite occlusive with irregular intra-vesical protrusion. Bladder was trabeculated and was generally congested. TURP was carried out, $54 \mathrm{gm}$ tissue was resected and it amounted to near complete resection. During resection, prostatic chips were rather yellowish but no abscess cavities or calculi were encountered. His postoperative recovery was uneventful.

Histopathology of the rescected tissue revealed dense xanthogranulomatous inflammation (Figure 1) mixed with eosinophils and foci of calcification. Benign prostatic glands were identified and no evidence of malignancy was noted. At 16 months follow-up patient remains symptom free. His serum PSA has decreased to $6 \mathrm{ng} / \mathrm{ml}$.

\section{Discussion}

A variety of granulomatous lesions of prostate have been described. Excluding the few cases in which the etiologic agent can be identified, the classification of the granulomatous lesions within the prostate remains controversial [1]. Infective agents that have been implicated in the spe-

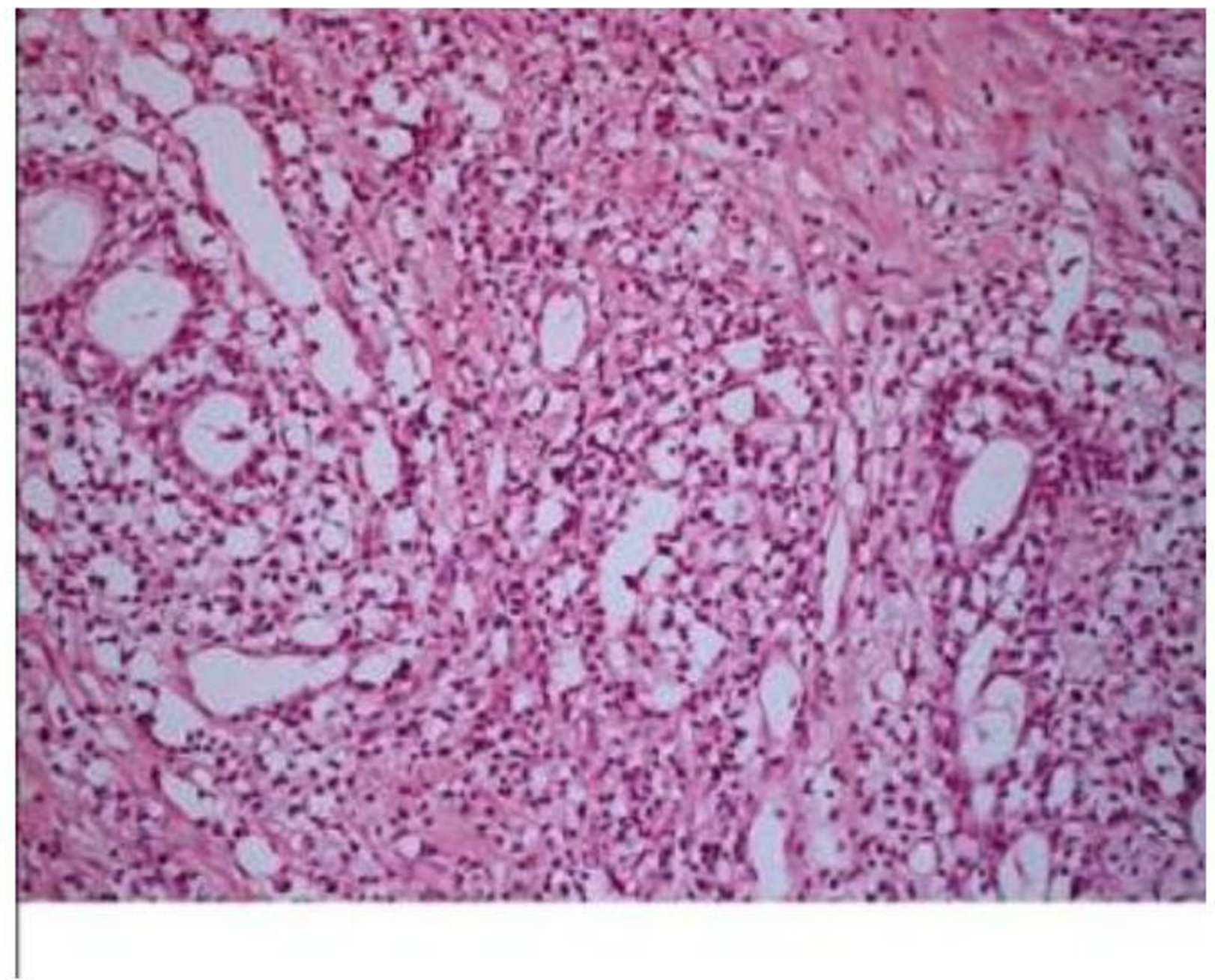

Figure I

Photomicrograph showing intense infilteration of prostate with lymphocyte, plasma cells and xanthoma cells (marked with arrow). $H \& E \times 200$. 
cific granulomatous prostatitis include various fungi, Treponema pallidum and most commonly Mycobacterium tuberculosis. The most commonly diagnosed granulomatous lesion within the prostates has been of nonspecific granulomatous prostatitis $[3,4]$.

The etiology and pathogenesis of this morphologically distinct lesion remains unknown. It is thought to represent a reaction to inflammatory products and altered prostatic secretions released from obstructed ducts [5]. Recently one study has linked this condition to an autoimmune disease [6]. The typical lesion in granulomatous prostatitis consists of a large nodular infiltrate of epitheliod histiocytes, lymphocytes and plasma cells occupying many prostatic lobules.

The distinctive feature of xanthogranulomatous prostatitis is the presence of large number of "foamy macrophages" (histiocytes) in the inflammatory cell infiltrate. Using an immuno-histological techniques, "T" lymphocytes are in close association with damaged epithelium while "B" lymphocytes occur in more peripheral location or form follicular structures [7]. A xanthogranulomatous pattern or prominence of epithelioid histiocytes sometimes bears a resemblance to high-grade prostatic carcinoma [8] and immunohistochemical panel has been proposed that can reliably distinguish between these two conditions [9]. However, on rare occasions granulomatous prostatitis and prostatic carcinoma may coexist [10].

Xanrthogranulomatous inflammation is well known in the kidney and gallbladder but prostate is rare site for this lesion. Less than 10 cases have been reported in the literature.

Average age at the time of diagnosis is early sixties, with a wide range from twenties to the very elderly. Clinically the symptoms are those of either urinary obstruction or a severe lower urinary tract infection [5]. On digital rectal examination, it is difficult to distinguish from prostatic carcinoma [11] as the prostate feels hard and nodular. In addition, this condition can cause elevation in serum PSA level. In one study, serum PSA ranged from less than 0.5 $\mathrm{ng} / \mathrm{ml}$ to $114 \mathrm{ng} / \mathrm{ml}$ (mean $12.7 \mathrm{ng} / \mathrm{ml}$ ) [4]. This increase of PSA level is usually transient [12]. In the present case serum PSA was markedly elevated at $150 \mathrm{ng} / \mathrm{ml}$ and this high level of PSA has not been reported in the literature previously. In spite of the very high serum PSA his bone scan was within normal limits. After transurethral resection of prostate, serum PSA level decreased to $6 \mathrm{ng} / \mathrm{ml}$. On transrectal ultrasonography (TRUS) and magnetic resonance imaging (MRI) there is no pattern that allows a specific diagnosis of granulomatous prostatitis or differentiate it from prostatic carcinoma [13]. Hence, the diagnosis of xanthogranulomatous prostatitis is made on histological examination of prostate.

\section{Conclusion}

Xanthogranulomatous prostatitis is uncommon and may simulate prostatic carcinoma both clinically and microscopically. There are no specific radiological features. Knowledge of this condition and close co-operation with pathologist is necessary for the diagnosis of xanthogranulomatous prostatitis.

\section{Competing interests}

The author(s) declare that they have no competing interests.

\section{Authors' contributions}

MR: Preparation of manuscript, NY: Histopathological examination of submitted prostatic tissue and preparation of microphotographs. Both authors read and approved the final manuscript.

\section{Acknowledgements}

Written consent was obtained from the patient for publication of this case report.

\section{References}

I. Epstien JI, Hutchins GM: Granulomatous prostatitis: distinction among allergic, non-specific and post-transurethral resection lesions. Hum Pathol 1984, I 5:81 8-825.

2. Srigley JR: Benign mimickers of prostatic adenocarcinoma. Mod Pathol 2004, I 7:328-348.

3. Mohan H, Bal A, Punia RP, Bawa AS: Granulomatous Prostatitis an infrequent diagnosis. Int J Urol 2005, I 2:474-478.

4. Oppenheimer JR, Kahane H, Epstein JL: Granulomatous prostatitis on needle biopsy. Arch Pathol Lab med 1997, I 2 1:724-729.

5. Epstein JI: The prostate and seminal vesicles. In "Diagnostic Surgical Pathology" 2nd edition. Edited by: Sternberg SS. Raven Press. New York USA; 1994: 1807-1848.

6. Alexander RB, Mann DL, Borkowski AA, Fernandez-Vina M, Klyushnenkova EN, Kodak J, Propert KJ, Kincaid M: Granulomatous prostatitis linked to HLA-DRBI*I50I. Urology 2004, I7I(6 pt I):2326-2329.

7. Bryan RL, Newman J, Campbell A: Granulomatous prostatitis. A clinicopathological study. Histopathology 1991, 9:453-457.

8. Bostwick DG, Chang L: Overdiagnosis of prostatic adenocarcinoma. Semin Urol Oncol 1999, 17:199-205.

9. Presti B, Weidner N: Granulomatous prostatitis and poorly differentiated prostatic carcinoma. Their distinction with the use of immunohistochemical methods. Am J Clin Pathol 1991, 95:330-334.

10. Val-Bernal JF, Zaldumbide L, Garijo MF, Gonzalez-Vela MC: Non specific (idiopathic) granulomatous prostatitis associated with low-grade prostatic carcinoma. Ann Diagn Pathol 2004, 8:242-246.

II. Miekos E, Wlodarczyk W, Szaram S: Xanthogranulomatous prostatitis. Int Urol Nephrol 1986, 18:433-437.

12. Speights VO Jr, Brawn PN: Serum prostate specific antigen levels in non-specific granulomatous prostatitis. Br J Urol 1996, 77:408-410.

13. Naik KS, Carey BM: The transrectal ultrasound and MRI appearances of granulomatous prostatitis and its differentiation from carcinoma. Clin Radiol 1999, 54:173-175. 